Diagnostic Methods in Veterinary Medicine

By Prof. Geo. F. Boddie. With a chapter on Diagnosis of Poultry Diseases by Dr. J. G. Campbell. Fifth edition. Pp. ix +420. (Edinburgh and London: Oliver and Boyd, Ltd., 1962.) 30s. net.

$\mathrm{T}$ HIS is a good book written by a clinician for clinicians. The arrangement is consequently according to the demands of the man observing a case. The general clinical everyday methods of observation and examination are given most of the space in the text, and special and elaborate systems of diagnosis are, in general, relegated to special chapters. Nine of the twenty-one chapters are concerned with body systems, and the amount of elinical detail covered is extraordinarily complete.

Specific infective processes are less completely covered and many that might lead the veterinarian to consult the book, for example, melioidosis or coccidioidomycosis, are outside its scope.

There is much more in the book than is indicated in the contents pages. Tables that are given in sequence in certain chapters might be numbered serially throughout the volume and listed as such on a preliminary page. With such a mass of essential information some greater breakdown showing where special items are to be found would help a reader.

For the practitioner on the farm or in the town the book is an essential source-book to be consulted at every contingency. The publishers' share in the work is up to the standard to be expected of them.

W. A. Poor

\section{Synovial Joints}

Their Structure and Mechanics. By C. H. Barnett, Prof. D. V. Davies and Prof. M. A. MacConaill. Pp. $x i+304$. (London: Longmans Green and Co., Ltd., 1961.) 50s. net.

7 HIS book sets out, at not too great a length, the modern views on most aspects of synovial joints. It is divided into four sections, the first dealing with the structure and composition of the various components of joints, and the second with such physiological topics as their nutrition, repair and development. The third section is an entirely non-mathematical treatment of the mechanics of joint movement (though adequate in its way, this section would have been improved by the addition of an extra chapter setting out some of the ideas in a rigid mathematical form). Various functional aspects are discussed in a final, shorter section.

The medically qualified reader, for whom the book is primarily intended, will find it most useful. The non-medical biologist, provided he can accept the extensive use of anatomical terms, should find that there are several chapters to interest him. The anatomical emphasis is very strong, reflecting the fact that all three authors are in anatomy departments. Other disciplines have not been ignored, but some of the biochemical asides could be misleading to the uninitiated. Although the individual authorship of certain passages is here and there detectable, the three authors have achieved a commendable degree of uniformity of style. The overall balance is good, though a few hobby horses have been ridden rather hard. The book is well documented, with more than 400 references, which appear to have been well chosen. The bibliography has been made all the more useful by the inclusion of an author index.
Progress in Operations Research

Vol. 1. Edited by Russell L. Ackoff. (Publications in Operations Research, No. 5.) Pp. xii+505. (Now York and London: John Wiley and Sons, Inc., 1961.) $92 s$.

THIS book, the first of a set of review volumes dealing with research methods, is number five in the series Publications in Operations Research. The set is to be a basic reference work, and, if this first volume is a guide, will undoubtedly be just that: a reference rather than an exposition. Apart from chapters of a general character, on subjects such as "The Meaning, Scope, and Methods of Operations Research", there are chapters dealing with subjects carrying specific mathematical apparatus, such as inventory theory, programming, Markov and queueing processes, sequencing theory and replacement theory. But these chapters, while they will be of value from the bibliographical point of view, are intensely unsatisfying. The reader is likely to feel insecure in that he will have been taken on a quick tour of inspection of some field, without being able to linger on detail at any point. The only exception to this seems to be the chapter by Prof. Morse on the dynamics of operational systems, which is excellent in that it combines a fine, expository power with some real mathematical technique.

For the postgraduate student contemplating entry into the field of operations research, the present book will be valuable in that it gives a quick bird's-eye view of practically all the methods so far used. There is also an ample bibliography at the end of each chapter to guide future reading, and the book, on the whole, achieves its aim of making the content of recent work in operations research readily available. L. S. GODDARD

Transformers and Generators for Power Systems Their Behaviour, Capabilities and Rating. By R. Langlois-Berthelot. Translated and revised in collaboration with Lieut.-Colonel H. M. Clarke. Pp. 541. (London: Macdonald and Co. (Publishers), Ltd., 1960.) 65s. net.

7 HE writer is known, not only as a distinguished

French engineer but also as the author of a series of four text-books which have been in use by French engineers and in the French colleges for several years. The present volume, together with the earlier work entitled Electro-magnetic Machines, covers the range of the four French books. They are, however, not exact translations but have been adapted to British needs with the help of Lieut.-Col. H. M. Clarke. As would be expected, the book takes full account of modern developments and, moreover, has a very valuable bibliography.

The book is of particular value to engineers interested in transformers and synchronous machines in relation to their application rather than to questions of detailed design. All the important practical operating problems are discussed, ranging from insulation and heating to steady and transient performance. It is of considerable interest to advanced students in the electrical power field, but in Britain it is of less value for undergraduate students because of the growing tendency in college courses to concentrate more on physical fundamentals than on the techniques used for exploiting them. Very little time is devoted nowadays in an undergraduate course to the subjects covered by this 540-page book.

B. ADKIN 